\title{
SIMULATION ANALYSIS OF A NEW CHIPS RECYCLING PROCESS TERMED FORMING EXTRUSION CUTTING
}

\author{
Deng, W. J.; Zhang, J. Y.; Liu, L. W.; He, D. \& Xia, W. \\ School of Mechanical and Automotive Engineering, South China University of Technology, \\ Guangzhou 510641, China \\ E-Mail: dengwj@scut.edu.cn
}

\begin{abstract}
Every year an enormous amount of metal scraps are produced from machining, causing waste and pollution. The existing recycling methods, such as melting and solid state recycling could not solve the problem of cumbersome processes and high costs, while in this study, a novel chips recycling process, namely the Forming Extrusion Cutting (FEC) was provided. It could turn irregular chips into grooved strips with industrial value during cutting, resulting in advantages such as high efficiency, low costs and high flexibility.

In this study, the FEC deformation was studied through finite element model analysis, while various structures of pure copper grooved strips were prepared with forming conservation rates beyond $80 \%$, confirming that the FEC could be adjustable in the production of strips with various groove structures. Furthermore, the grooved strips surfaces had abundant substructures, which meant that the grooved strips prepared by FEC had a wide range of applications and high potential for development in the heat transfer field.

(Received, processed and accepted by the Chinese Representative Office.)
\end{abstract}

Key Words: Chips Recycling, Forming Extrusion Cutting (FEC), Metal Cutting, FEM, Grooved Strips

\section{INTRODUCTION}

Subtractive manufacturing constitutes the most important part in modern industry, while the production scraps cause waste and pollution. Consequently, scrap recycling is of high significance. The recycling of low-sized metal scraps, such as chips produced by machining tools, is faced with various challenges, as in the traditional recycling methods, the irregular geometry and the higher amount of adhesion (oils and cooling lubricants), leading to the increased loss of chips in melting compared to the bulk material. To reduce this waste, researchers developed many other recycling methods without melting, such as powder metallurgy [1], pressing and hot extrusion [2], sintering and forging operations [3, 4], or severe plastic deformation such as equal channel angular pressing [5, 6]. This was conducted to prepare powder or bulk materials from chips and certain recycled materials have higher mechanical properties compared to as-cast materials [7].

Except the methods that include chip conversion into a blank material, other researchers announced that chips could also be reused to produce finished products, which highly expands the application range of chip recycling [8]. Moloodi and Raiszadeh [9] applied the sinteringdissolution to the fabrication of aluminium foams from AA336 turning scraps, while Omoregie [10] prepared sandcrete building blocks with significant increase in compressive strength, through the attachment of steel chips as a consolidation material. Adversely in these recycling methods, the melting was replaced with other operations, which did not reduce the process flows from chips to products, retaining a high level of recycling cost.

In this study, a novel process for chip recycling, namely the Forming Extrusion Cutting (FEC) was developed. Radically different from other available recycling processes, the FEC process is a one-step operation of two functions: machining and chip recycling in one process. It constitutes an approach, in which, the chips could be directly turned into grooved strips 
during machining. The recycling operation acted on the chip forming stage instead of the chips separation, in order for several intermediate processes to be reduced, which fits the opinion that considering the recycling cost in the stage of production development [11].

As schematically illustrated in Fig. 1, in FEC, a constraining tool is added in normal cutting process to the point of chip formation, building an extrusion channel between the cutting tool and the constraining tool. The workpiece material sustains constraint from this channel, which would be the forming dynamic, to squeeze the material into the groove structure on the constraining tool. Consequently, the chips are formed into grooved strips subsequently to flowing out of the channel.

As a recycling process for chips as well as a process for grooved strips production, the FEC has several advantages. Firstly, it has high efficiency, as the waste material is directly converted into grooved strips in one direct deformation step. Secondly, it is energy and costefficient, as the single-stage nature of this process reduces the requirement for intermediate energy-intensive operations and vast infrastructure in other recycling processes. Thirdly, it is flexible, as it mainly acts on the formation of chips, having low effect on the processed surface of the bulk material, consequently adapted to various types of cutting processes. Therefore, the FEC has a strong potential for further development.

Through the design change of the groove structure on the constraining tool, the grooved strips structure as produced by FEC could be adjusted to meet the industrial demands, such as for high surface area in the heat transfer field. Due to the thermodynamic effect during machining, the surface of the grooved strips has abundant substructures, which could also apparently increase the specific surface area of the groove, being an advantage to other fins with smooth surface. This implied that the grooved strips produced by FEC have a significantly wide use in the heat transfer field.

This article deals with principal investigations of the FEC process, focusing on the deformation process and forming performance. Finite element modelling (FEM) analysis was applied to discover the variation of deformation parameters during the process, where the grooved strips with various structures were prepared to observe the corresponding forming performance and surface structure. The mechanism and equipment of FEC are described in section 2; the setting of FEM is presented in section 3, while the experimental details are presented in section 4. Finally, the results of this study were evaluated and presented in section 5, whereas an outlook for future investigations is presented in section 6 .

\section{MECHANISM AND EOUIPMENT}

The FEC was developed from extrusion cutting, which was firstly proposed by De Chiffre to produce soft metal chips with geometrically controlled chip formation. Brass strips were successfully produced [12]. The schematic of extrusion cutting is presented in Fig. 1 a, while the constraint at the point of chip formation transformed the simple cutting into a hybrid deformation process. During extrusion cutting, an important parameter, called chip compression ratio $(\lambda)$, is given in Eq. (1):

$$
\lambda=\frac{t_{c h}}{t_{d}}
$$

where, $t_{d}$ is the cutting layer thickness, while $t_{c h}$ is the chip thickness.

Through the groove structure attachment on the constraining tool, a forming dynamic was added to the chip, shaping it into the relevant groove structure, as presented in Fig. $1 \mathrm{~b}$. In FEC, the chip thickness $t_{c h}$ represents the shortest distance between the constraining tool and the cutting tool, as presented in Fig. 1 b. As the chips were formed into grooved strips, the material deformation in FEC did not consist of the simple shear and plain strain state, such as 
in traditional extrusion cutting, requiring further investigations to discover the relationship between the working parameters and the deformation process.

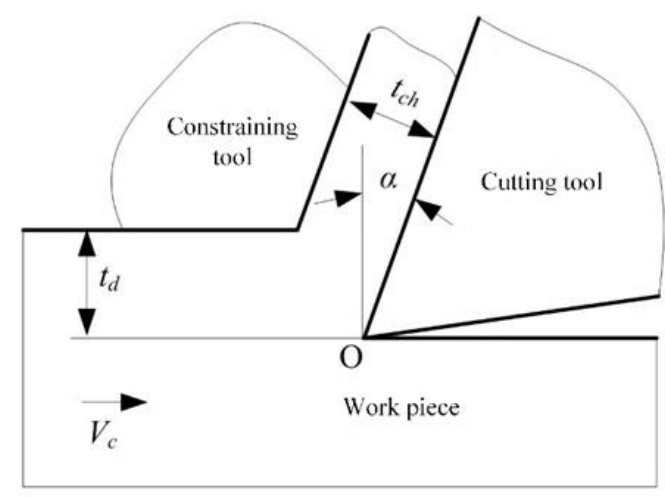

a) Schematic of extrusion cutting

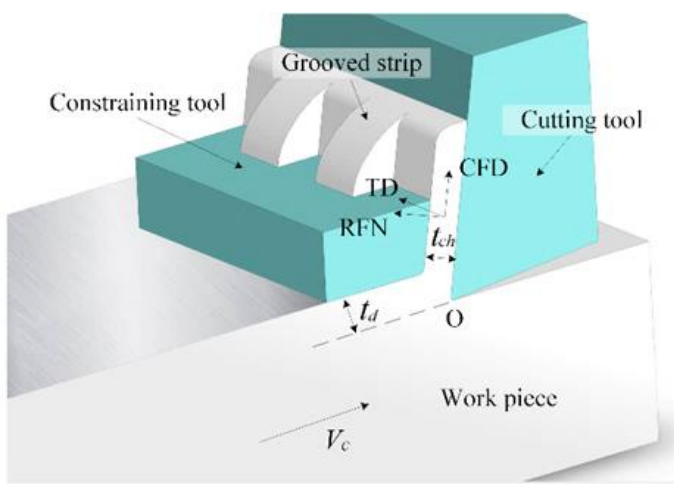

b) Schematic of FEC (CFD: chip flow direction;

TD: transverse direction; RFN: rake face normal)

Figure 1: Schematic of extrusion cutting and Forming Extrusion Cutting (FEC).

To produce grooved strips with various structures and parameters for investigation, a combined tool was designed and presented at the left of Fig. 2, whereas the setup for the process is presented at the right of Fig. 2. The constraining tools with various structures could be replaced, while both $t_{d}$ and $t_{c h}$ could be adjusted through the shim thickness changes.

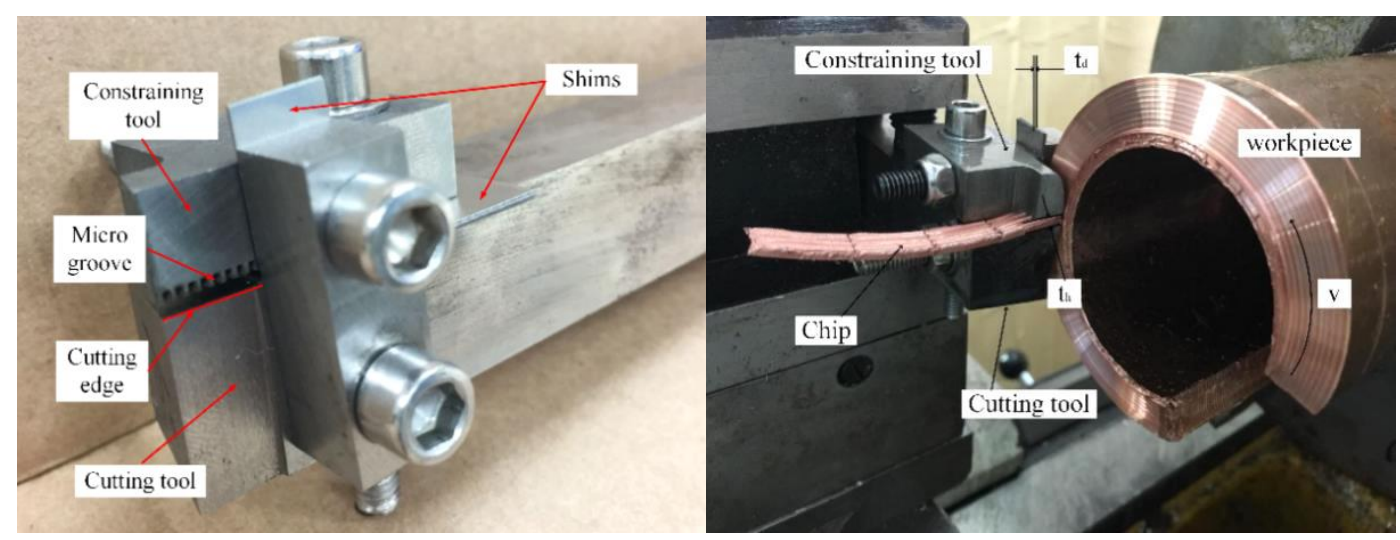

Figure 2: Combined tool (left) and setup (right) of machining experiments.

\section{FINITE ELEMENT MODELLING}

The described finite-element model of FEC is an important element in the extrusion cutting with groove structure establishment. Compared to traditional extrusion cutting, the FEC produces changes that led from plane strain machining to 3-D strain machining, while the distributions of strain and stress during the process became significantly complex.

The simulations in this study were conducted with a commercial FEM code DEFORM3D, which was based on an updated Lagrangian formulation, being suitable for high plastic deformation analysis [13]. The basic model is presented in Fig. 3. Four faces, such as the $\mathrm{ADEH}, \mathrm{ABCD}, \mathrm{EFGH}$ and $\mathrm{ABGH}$ of the workpiece, were constrained in all directions and the tools were set to move in a specific direction with an assigned cutting speed $V$.

A rotating workpiece was transformed into a linear machining condition to provide simplicity in simulation. Consequently, the work piece in this model could be simplified into a cuboid, being considered as a plastic body. Fig. 3 (right) also presents the initial finite element mesh result. A tetrahedral of 100000 elements thermally coupled was utilized in the work piece. 

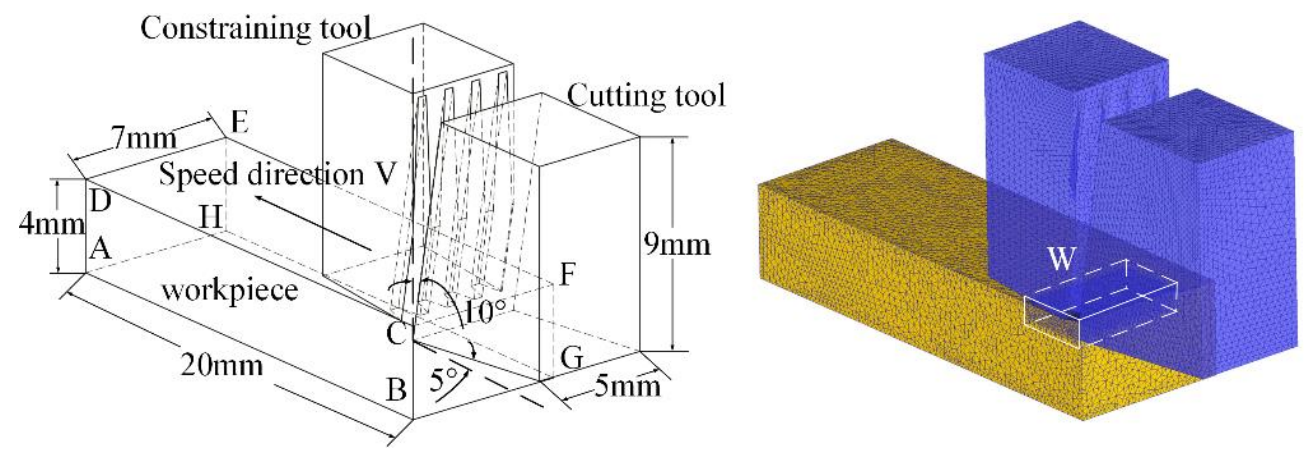

Figure 3: Basic model of extrusion cutting with groove structure.

The workpiece material was selected to be from pure copper, as pure copper and aluminium alloys are the two most widely utilized materials for fin plate production, while pure copper has a better ductility. Table I presents the physical properties of pure copper. Among various mathematical models, the Johnson-Cook material model was applied as a material constitutive model. It was selected for the research study, also providing a good description of the material flow stress behaviour regarding the strain, the strain rate and the temperature, which could be represented by Eq. (2):

$$
\bar{\sigma}=\left[A+B \cdot \varepsilon^{n}\right] \cdot\left[1+C \cdot \ln \left(\frac{\vec{\varepsilon}}{\vec{\varepsilon}_{0}}\right)\right] \cdot\left[1-\left(\frac{T-T_{\text {room }}}{T_{\text {melt }}-T_{\text {room }}}\right)^{m}\right]
$$

where, $\varepsilon$ is the real plastic strain rate, $\vec{\varepsilon}$ is the equivalent plastic strain rate, $\vec{\varepsilon}_{0}$ is the reference plastic strain rate, $\mathrm{A}$ is the yield stress, $\mathrm{B}$ is the strain hardening coefficient, $\mathrm{C}$ is the strain rate sensitivity coefficient, $\mathrm{n}$ is the strain hardening exponent, $m$ is the thermal dependence coefficient, $T_{\text {room }}$ is the temperature of the workpiece material (room temperature) and $T_{\text {melt }}$ is the melting temperature for the workpiece material.

Table I: Physical properties of pure copper.

\begin{tabular}{|l|c|}
\hline Material & Pure cupper \\
\hline Density, $\rho(\mathrm{kg} / \mathrm{m} 3)$ & $8.96 \times 10^{3}$ \\
Elastic modulus, $E(\mathrm{GPa})$ & 108 \\
Poisson's ratio, $v$ & 0.333 \\
Thermal conductivity, $W(\mathrm{~m} \cdot \mathrm{K})$ & 122.613 \\
Expansion coefficient, $\alpha(\mu \mathrm{m} / \mathrm{m} / \mathrm{K})$ & 17.5 \\
Tmelt $\left({ }^{\circ} \mathrm{C}\right)$ & 1082.85 \\
Heat capacity $\left(\mathrm{N} / \mathrm{mm}^{2} / \mathrm{K}\right)$ & 3.16032 \\
\hline
\end{tabular}

Each constant of the pure copper Johnson-Cook material model is listed in Table II.

Table II: Material constants of the J-C flow stress model for pure copper.

\begin{tabular}{|l|c|c|c|c|c|c|}
\hline Material & $A(\mathrm{Mpa})$ & $B(\mathrm{Mpa})$ & $n$ & $C$ & $m$ & Tmelt $(\mathrm{K})$ \\
\hline Pure cupper & 90 & 292 & 0.31 & 0.025 & 1.09 & 1356 \\
\hline
\end{tabular}

The cutting tool and constraining tool in the simulation were considered as a rigid body and several key parameters are listed in Table III. The temperature-dependent material properties were considered in the simulation. Following, the thermal conductivity and heat capacity of the cutting tool material are also listed in Table III.

Four different structures of grooves on the chip were set in the simulation, as shown in Fig. 4. Several structures with the best forming performance were selected for the experiment. The structures included the rectangle groove (R), the isosceles trapezoid groove of $75^{\circ}$ in base angle $(\mathrm{Tr})$, the equilateral triangle groove $(\mathrm{T})$ and the sinusoidal waveform groove (S). Each 
groove with the designed micro groove cross-sectional geometry and dimensions is shown in Fig. 4. The other working parameters are listed in Table IV.

Table III: Cutting tool geometry specification and material properties used in simulation.

\begin{tabular}{|l|c|l|c|}
\hline \multicolumn{1}{|c|}{ Tool geometry specification } & Value & \multicolumn{1}{|c|}{ WC tool material properties } & Value \\
\hline Cutting tool nose radius $\left(^{\circ}\right)$ & 0 & Young's modulus $(\mathrm{Gpa})$ & 650 \\
Rake angle $\left({ }^{\circ}\right)$ & 10 & Poisson' ratio & 0.25 \\
Clearance angle $\left({ }^{\circ}\right)$ & 5 & Thermal expansion $\left(\times 10^{-6} / \mathrm{K}\right)$ & 5 \\
Constraining tool corner radius $(\mathrm{mm})$ & 0 & Emissivity & 0 \\
Channel length $(\mathrm{mm})$ & 6 & Thermal conductivity $(\mathrm{N} / \mathrm{s} / \mathrm{K})$ & 59 \\
& & Heat capacity $\left(\mathrm{N} / \mathrm{mm}^{2} / \mathrm{K}\right)$ & 15 \\
\hline
\end{tabular}

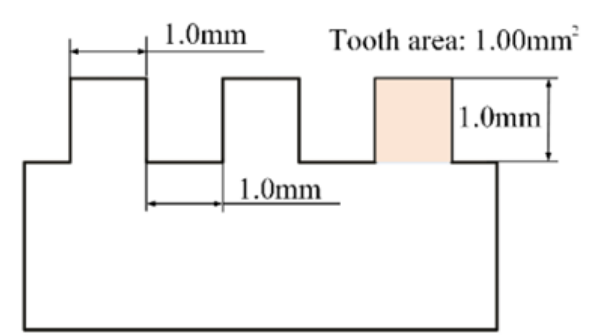

a) Rectangle groove $(\mathrm{R})$

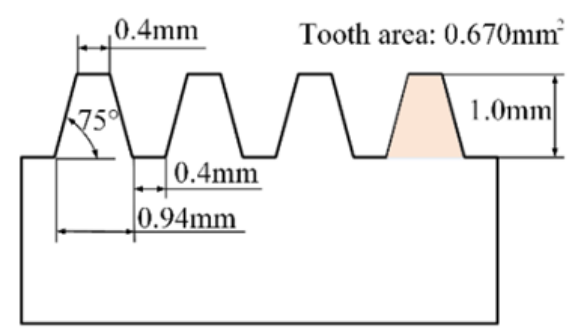

b) Isosceles trapezoid groove (Tr)

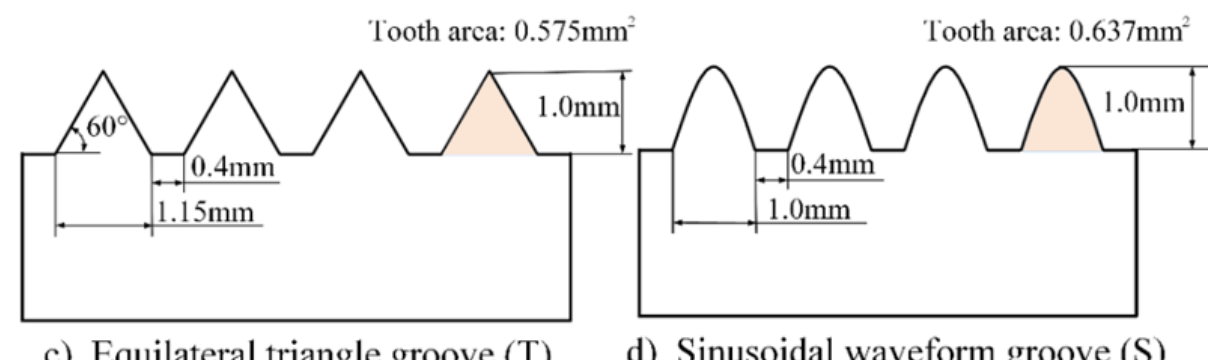

c) Equilateral triangle groove $(\mathrm{T})$

d) Sinusoidal waveform groove (S)

Figure 4: Four structures of grooves applied in simulation.

Table IV: Other working parameters in FEM.

\begin{tabular}{|l|c|}
\hline Parameters and units & Value \\
\hline Cutting velocity $V_{c}(\mathrm{~mm} / \mathrm{s})$ & 0.09 \\
Cutting depth $t_{d}(\mathrm{~mm})$ & 0.6 \\
Squeeze thickness $t_{c h}(\mathrm{~mm})$ & 0.48 \\
Rake angle of the cutting tool $\left({ }^{\circ}\right)$ & 10 \\
Constraining tool corner radius $(\mathrm{mm})$ & 0 \\
Initial temperature $(\mathrm{K})$ & 293 \\
Air convection $(\mathrm{N} / \mathrm{s} / \mathrm{mm} / \mathrm{K})$ & 0.02 \\
Heat transfer coefficient $(\mathrm{N} / \mathrm{s} / \mathrm{mm} / \mathrm{K})$ & 40 \\
Friction coefficient & 0.6 \\
\hline
\end{tabular}

\section{EXPERIMENTAL INVESTIGATION}

During the FEM analysis, all structures demonstrated the feasibility of chips production with groove structures. Consequently, these structures were applied to the experiments, as presented in Fig. 5. The experiments were performed with a turning machine (C6140A; Guangzhou Machine, China), whereas the workpiece material was selected as a copper rod of commercial purity $(99.96 \%$ ) of $70 \mathrm{~mm}$ in diameter. The other cutting parameters utilized in the experimental studies corresponded to the simulation. 


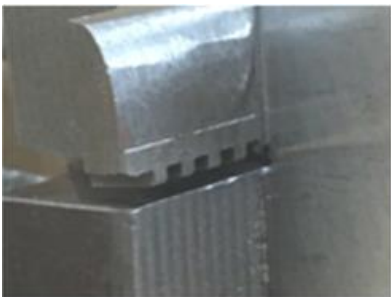

a) Rectangle groove (R)

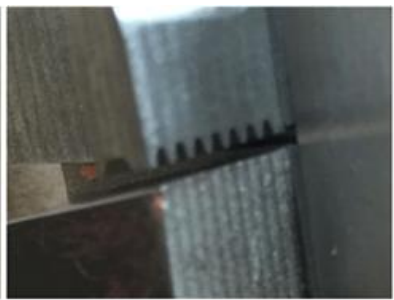

b) Isosceles trapezoid groove $(\mathrm{Tr})$

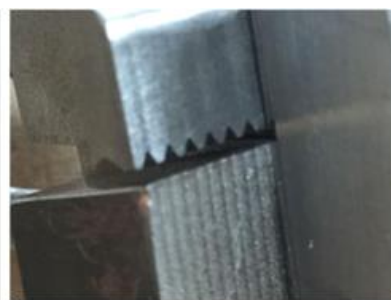

c) Equilateral triangle groove $(\mathrm{T})$

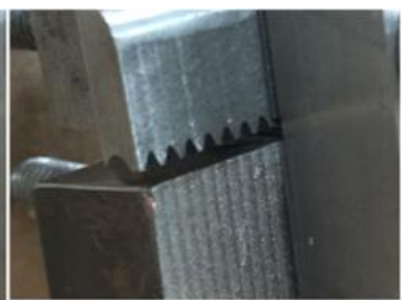

d) Sinusoidal waveform groove $(\mathrm{S})$

Figure 5: Four structures of grooves applied in experiments.

In this study, the formation of strips and the micro tooth of the final surface were the supposed outcomes of extrusion cutting forming. The micro tooth area was regarded as a key parameter for the micro-groove formation effect analysis in this study. The final micro tooth could be simplified as a trapezoid, even though the micro tooth could have a high number of shapes, as presented in Fig. 6.

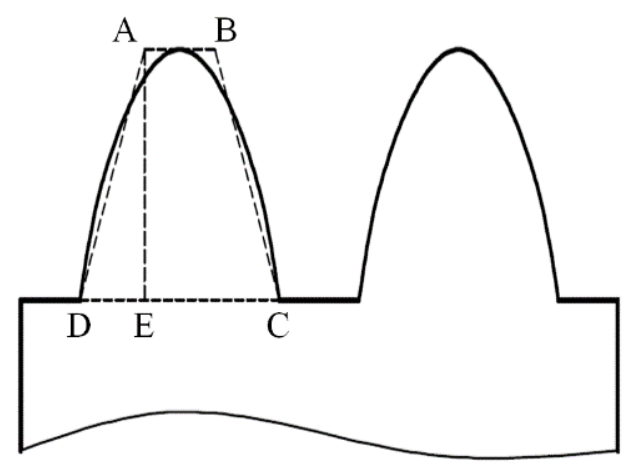

Figure 6: Geometry of micro tooth section approximation.

Regarding the trapezoid $\mathrm{ABCD}$, the micro tooth area can be calculated by Eq. (3):

$$
S=\frac{1}{2} \times(A B+C D) \times A E
$$

according to the contact conditions between the workpiece and the groove, where, $A B$ is the micro tooth top length, $C D$ is the micro tooth bottom length and $A E$ is the micro tooth height.

The micro tooth size and morphology of the extrusion cutting samples were measured with an ultra-deep microscope (VHX-1000E; KEYENCE, Japan). All samples were mounted with epoxy resin in rod shape of $25 \mathrm{~mm}$ in diameter, subsequently to ultrasonic cleaning. The samples were consequently ground down to $300 \mu \mathrm{m}$. At least 3 random cross sections of each sample were selected for measurements, whereas the micro tooth size of each cross section was measured 3 times. The mean micro tooth height, the micro tooth bottom length and the micro tooth top length were considered as the final micro tooth dimensions of the samples.

\section{RESULTS AND DISCUSSION}

\subsection{Surface micro-groove formation process}

Even though other parameters were set as consistent to each other, the deformation processes of the four structures were similar. In this section, the isosceles trapezoid groove of $75^{\circ}(\mathrm{Tr})$ base angle structure was considered as an example.

According to the contact conditions between the workpiece and the groove on the constraining tool, the process could be divided into four phases in general, as shown in Fig. 7: 
(1) When the cutting phase began, the chip was cut by the cutting tool and the preparation for entry to the extrusion channel. The constraining tool was not in contact with the chip and this phase was called the initial cut stage.

(2) When the combined tool continuously moved along with the chip length growth, it began to contact the constraining tool; the chip began to be squeezed in the constraint channel and the contact area mainly increased at the cross section. This was called the extrusion forming stage.

(3) With the continuous extrusion process, the load increase gradually reached a maximum value and the contact area mainly increased along the groove, whereas the extrusion machining reached a stable forming stage.

(4) At the final forming stage, the micro-groove structure chip exited the channel and continuously outflowed along the groove direction.

During the forming process, the key elements such as the effective stress, the effective strain and strain rate, the main cutting force and the thermal distribution could be useful to deformation discovery of the workpiece, as illustrated in Fig. 7.

Stress - Effective (MPa)

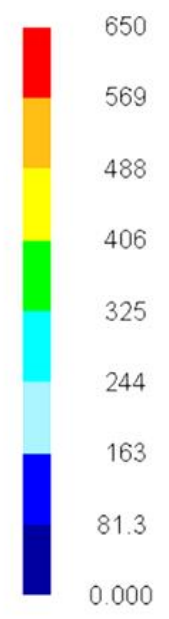

a)

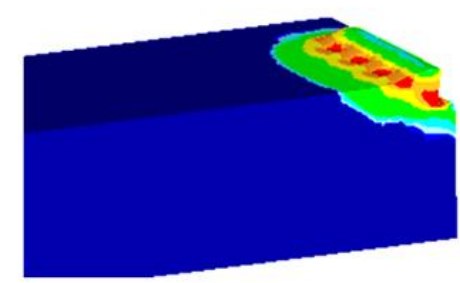

c)

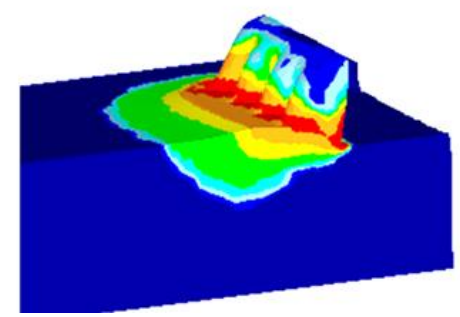

b)

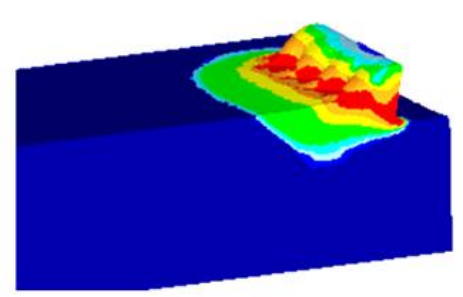

d)

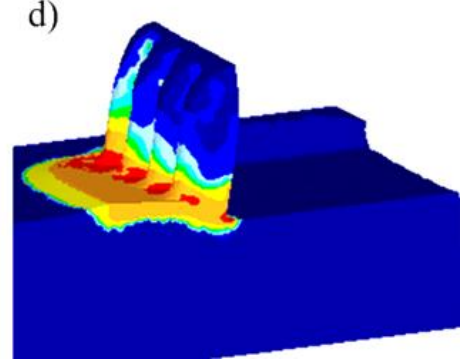

Figure 7: Effective stress distribution of various forming stages: a) initial cutting stage; b) extrusion forming stage; c) stable forming stage and d) final forming stage.

As presented in Fig. 7, effective stress was mainly distributed within the contact zone of the constraining tool and the workpiece as well as in the cutting tool and the workpiece, constantly expanding as the cutting process continued. At the second half of the forming channel, the material did not sustain high effective stress, since the cross section growth generally stopped at that location. Therefore, the entrance of the forming channel was the key point affecting the effective stress distribution during the process.

As presented in Fig. 8, the effective strain was relative low at the first stage. Until the extrusion forming stage, the effective strain was concentrated on the contact zone of the cutting tool and the workpiece, where the second and third deformation zones are. Also, at the groove surface on the workpiece, the effective strain was concentrated as the groove bottom, as the material at the bottom sustained lower chip compression ratio compared to the top of the groove. With the longitudinal growth of the chip, the effective strain concentration area also increased along the groove. Therefore, the top of the groove structure on the constraining tool was the key point affecting the effective strain distribution during the process. 
Strain - Effective $(\mathrm{mm} / \mathrm{mm})$

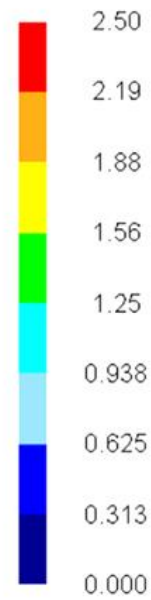

a)

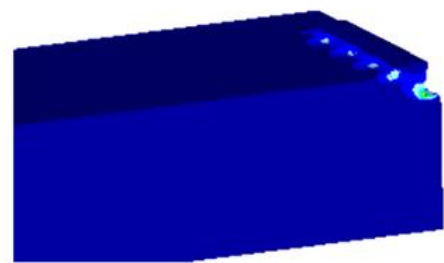

c)

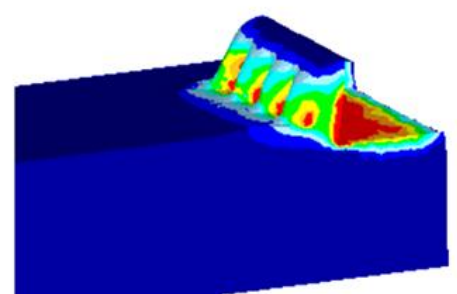

b)

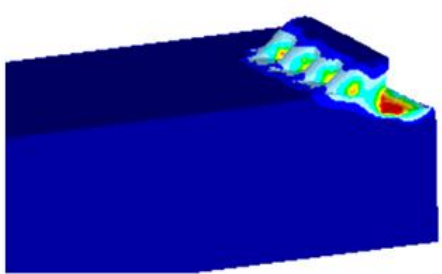

d)

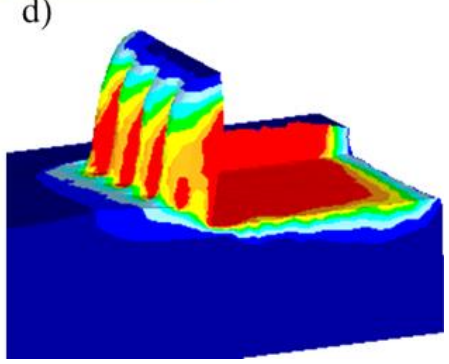

Figure 8: Effective strain distribution of various forming stages: a) initial cut stage; b) extrusion forming stage; c) stable forming stage and d) final forming stage.

According to Fig. 9, the effective strain was focused on the entrance of the forming channel, while the contour of it was focused on the rough surface of the workpiece. This demonstrated the material stacks frontier, whereas the other zones displayed rather low values. During the process of four stages, the effective strain rate of the area near the tool nose maintained a high value, while the other concentration regions effective strains were located the groove structure bottom on the entrance. All these areas did not transfer the stress along with the material flow, which implied that during the forming of the grooved strips, the main deformation occurred at the first and second deformation zones of the "base" part.
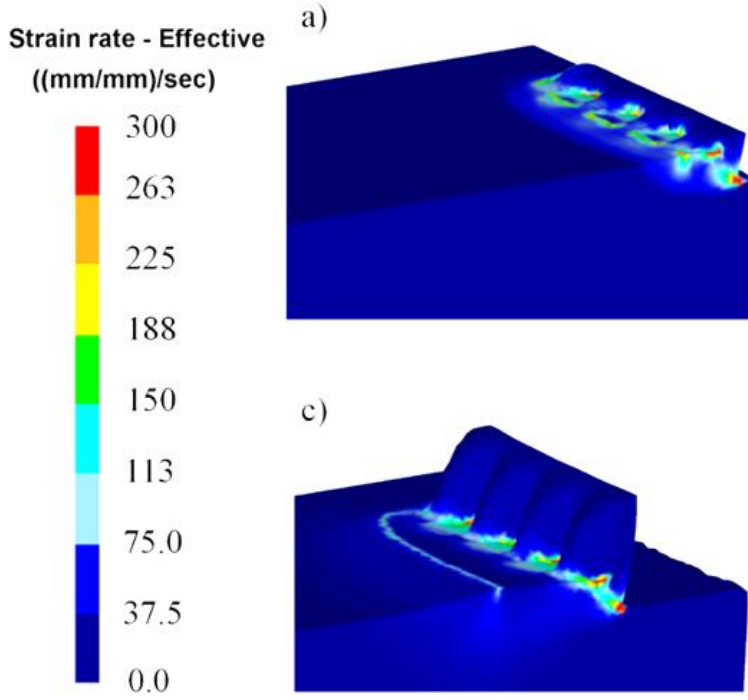

b)

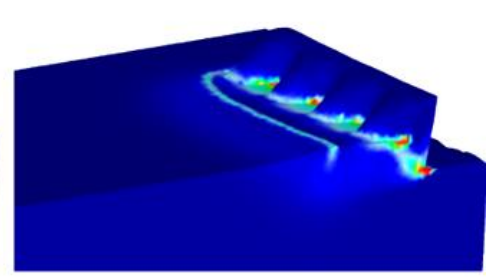

c)
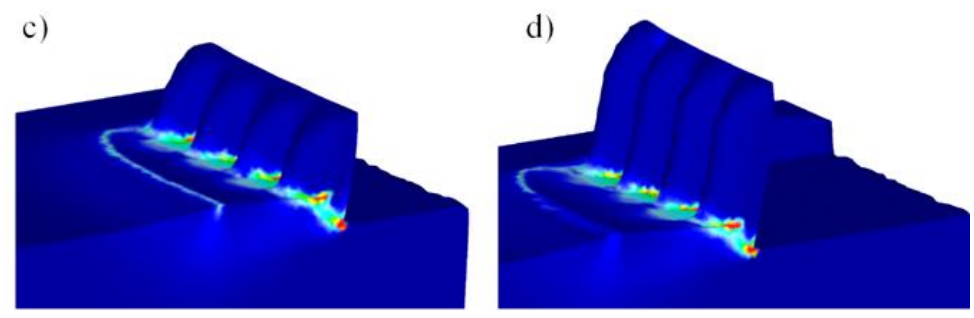

Figure 9: Effective strain rate distribution of various forming stages: a) initial cut stage; b) extrusion forming stage; c) stable forming stage and d) final forming stage.

The load curve of the process at the same cutting speed is presented in Fig. 10, divided into four parts according to the phase division. At the first stage, the rapid increase of load originated from the contact between the cutting tool and the workpiece, while the constraining tool was added to the process at the second stage. The load increase slowed down and began to fluctuate. During the main stage of tooth forming in the third part, the fluctuation continued with a gradual increase, which mainly resulted from the deformation resistance and the 
friction between the material and the groove structure on the constraining tool, during the contact area increase at the cross section. At the last stage, as the flow resistance of the material was retained stable, the load-time curve also demonstrated a stable trend.

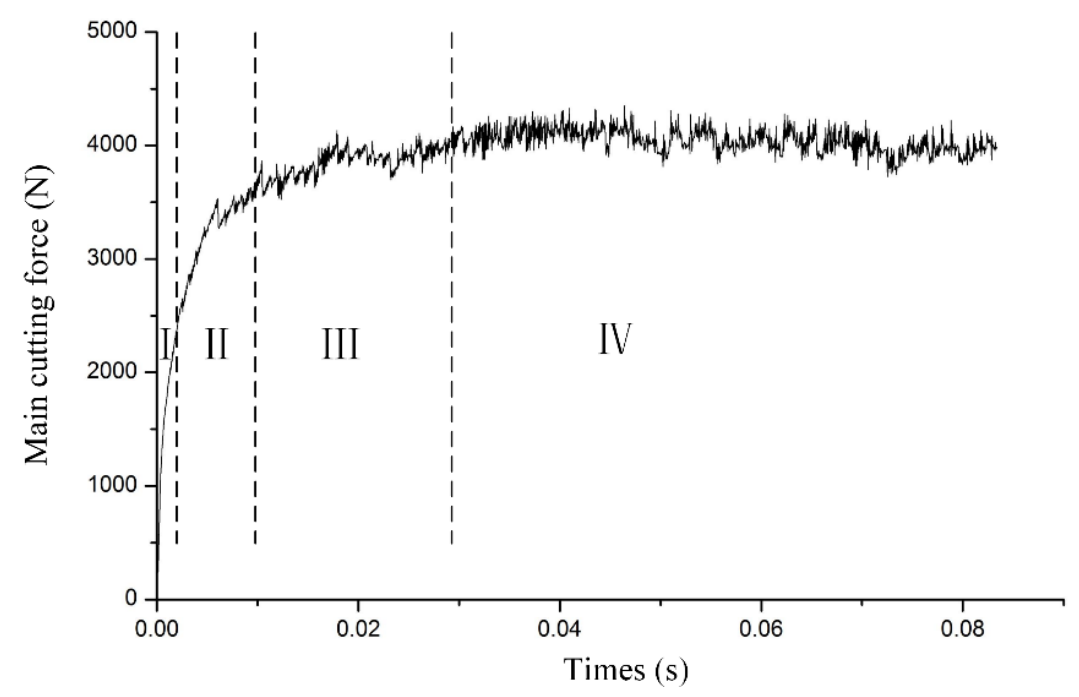

Figure 10: Load-time curve during processing: I) initial cut stage; II) extrusion forming stage; III) stable forming stage and IV) final forming stage.

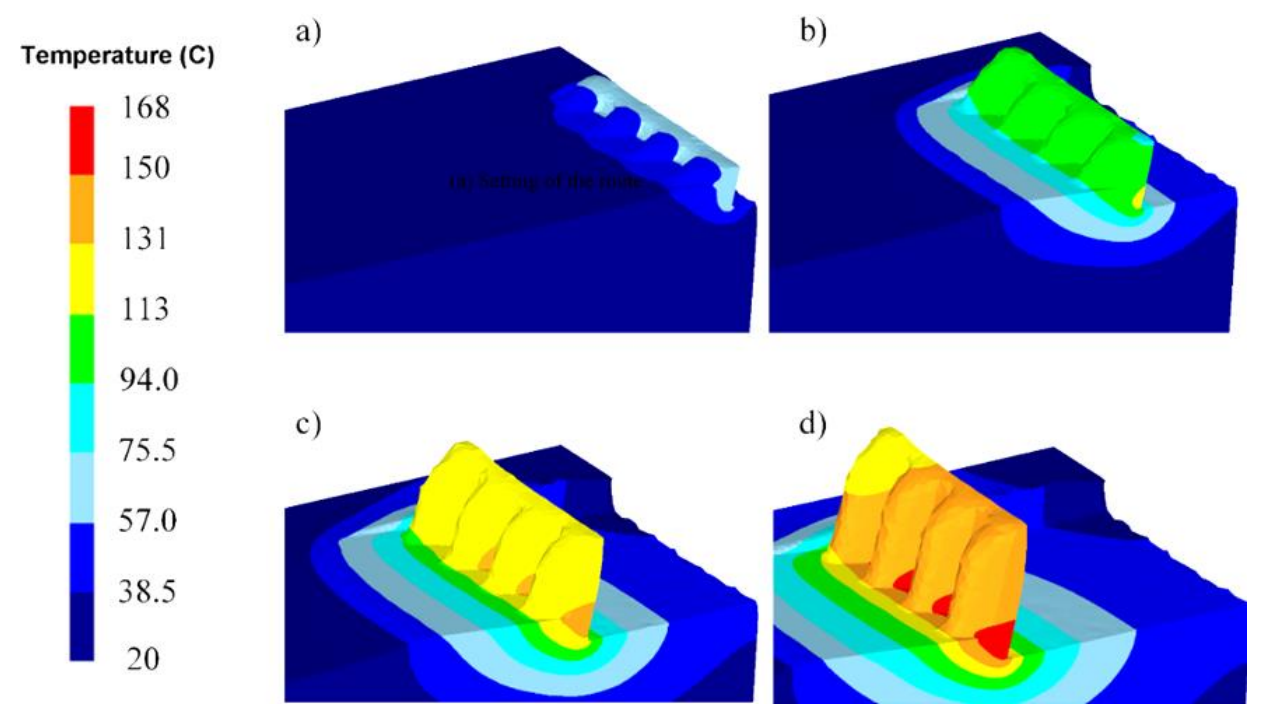

Figure 11: Temperature distribution on workpiece at various forming stages: a) initial cut stage;

b) extrusion forming stage; c) stable forming stage and d) final forming stage.

The thermal distribution constitutes one of the key elements in the deformation of the FEC process. Simultaneously affected by cutting and extrusion, the working temperature should be higher compared to the traditional cutting or cold extrusion process. The high temperature signified higher energy for the material, leading to the acceleration of both softening and plastic flow, which was beneficial to the groove formation. As presented in Fig. 11, during the four stages, the workpiece material temperature constantly increased. Also, the maximum temperature occurrence on the workpiece was focused on the second deformation area between the groove top on the constraining tool and the rake face of the cutting tool, where the workpiece sustained the most severe deformation. Besides the deformation distribution, this situation could be attributed to another reason, where the material could not totally fulfil the groove on the constraining tool. This consequently produced an improved heat radiation condition than the area in contact with the rake face of the cutting tool. 
Through the aforementioned parameter variations, it could be observed that during FEC, the tooth formation mainly proceeded at the stable forming stage. Most deformation occurred around the forming channel entrance, where it might be an critical point for further study and development of the FEC process.

\subsection{Groove structure and forming performance}

Groove strips were successfully produced during experimentation, whereas the comparison of the tools, the groove structure, the forming performance in FEM and the experiments are presented in Fig. 12. The resultant data of the forming area effects on the cross section are listed in Table $\mathrm{V}$.

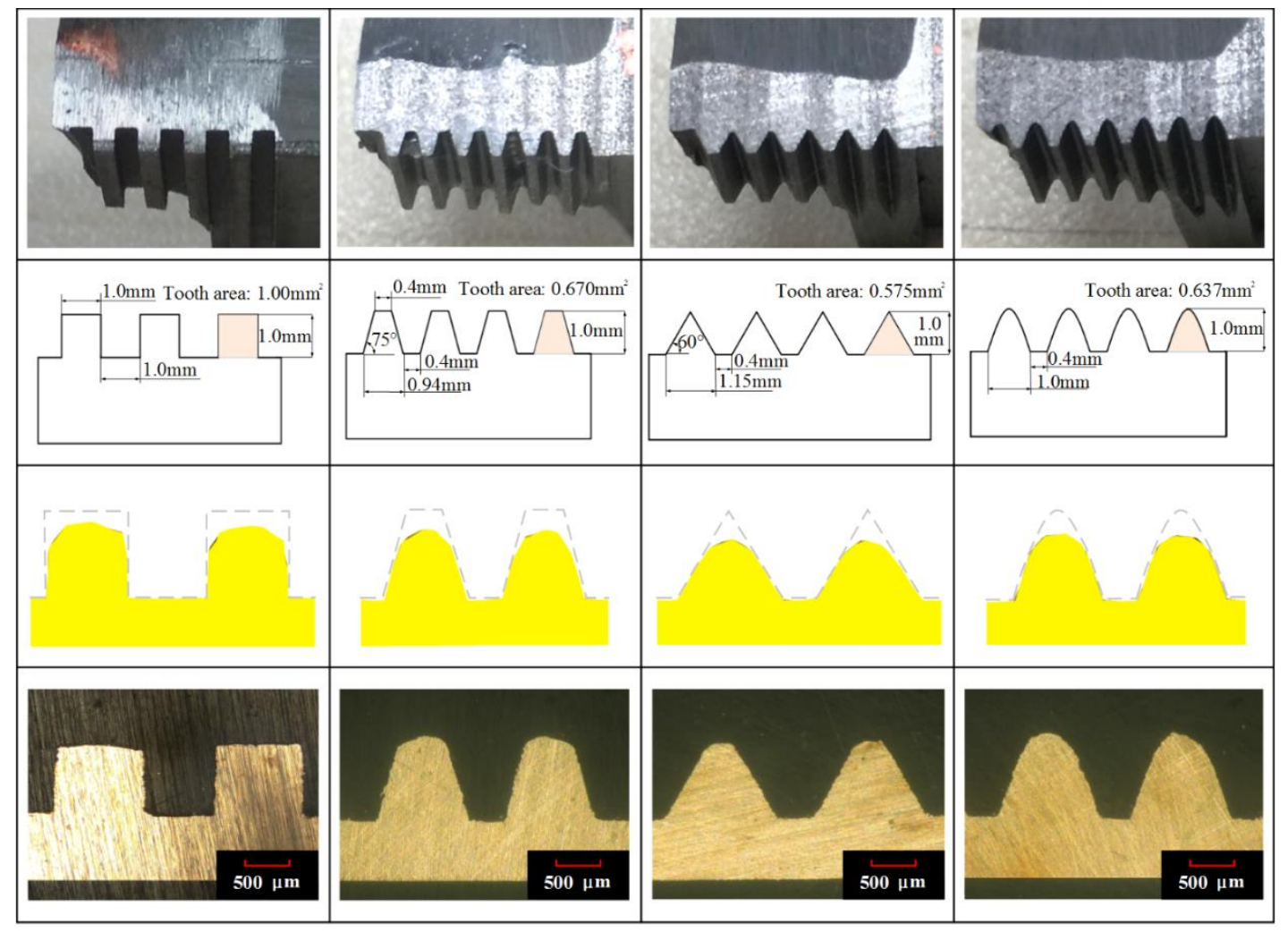

Figure 12: Forming performance of four structures in simulation and experimentation.

In Fig 12, the core contents constituted the morphologies of the cross sections of the chips, which intuitively demonstrate the forming performance. The dashed line in the FEM cross section of the chips presented the groove structure on the constraining tool, which could clearly demonstrate the forming conservation.

In Table $\mathrm{V}$, the experimental data are listed under the EXP line, whereas the relative errors between the data from FEM and the EXP are listed under the RE line, in percentages. The forming conservation rates were the percentage ratios between the forming area and the designed tooth area, which are presented in the conservation rate column.

Through the analysis of Table V and Fig. 12, all samples presented characteristics from the target structures. The rectangle groove had the best performance in the simulation, while the other three structures were similar in performance to each other. The rectangle groove structure performance could be observed for two reasons: firstly, among all structures, the top edge area of the rectangle groove was significantly higher than the other three structures. Consequently, the material sustained higher amount of forming pressure; secondly, the vertical side face displayed the least flow resistance along the extension orientation. 
Deng, Zhang, Liu, He, Xia: Simulation Analysis of a New Chips Recycling Process Termed ...

Table V: Micro tooth heights, forming area and conservation rates of various structures.

\begin{tabular}{|l|c|c|c|c|c|c|c|c|c|}
\hline \multirow{2}{*}{ Structure } & \multicolumn{2}{|c|}{ Micro tooth height (mm) } & \multicolumn{3}{|c|}{ Forming area $\left(\mathrm{mm}^{2}\right)$} & \multicolumn{3}{c|}{ Conservation rate (\%) } \\
\cline { 2 - 11 } & FEM & EXP & RE (\%) & FEM & EXP & RE (\%) & FEM & EXP & RE (\%) \\
\hline $\begin{array}{l}\text { Rectangle } \\
\text { groove (R) }\end{array}$ & 0.848 & 0.868 & 2.30 & 0.839 & 0.871 & 3.67 & 83.9 & 87.1 & 3.67 \\
\hline $\begin{array}{l}\text { Isosceles } \\
\text { trapezoid } \\
\text { groove (Tr) }\end{array}$ & 0.759 & 0.809 & 6.18 & 0.503 & 0.549 & 8.38 & 75.1 & 81.9 & 8.38 \\
$\begin{array}{l}\text { Equilateral } \\
\text { triangle } \\
\text { groove (T) }\end{array}$ & 0.650 & 0.690 & 5.80 & 0.452 & 0.473 & 4.44 & 78.6 & 82.3 & 4.44 \\
\hline $\begin{array}{l}\text { Sinusoidal } \\
\text { waveform } \\
\text { groove (S) }\end{array}$ & 0.731 & 0.791 & 7.59 & 0.470 & 0.520 & 9.62 & 73.8 & 81.6 & 9.62 \\
\hline
\end{tabular}

As presented in Table $\mathrm{V}$, all samples in the experiments displayed a forming conservation rate exceeding $80 \%$ and the relative error between the FEM data and the EXP data was retained at $10 \%$, which indicated both the forming ability and stability of this process. All experiments displayed a better workpiece performance compared to FEM. A possible explanation was that in FEM, the coulomb friction coefficient of the tools and the chip was 0.6, which might be suitable for the cutting tool, but too high for the constraining tools in practice.

\subsection{Substructures on surfaces}

Due to the thermodynamic effect, the surfaces of the grooved strips prepared by FEC were not smooth as the other groove products, having abundant substructures, as presented in Fig. 13.

In Fig. 13 b, the 3D photo of the sample, in Fig. 13 a as scanned with the ultra-deep microscope displayed the entire structure of the groove, while Fig. $13 \mathrm{c}, \mathrm{d}$ and e presented the morphologies on the top and bottom of the groove as well as the branch that could not be well presented in the 3D photo. Substructures such as wrinkles could be observed on the top of the groove, while the micro grooves and cracks at the groove bottom could not be observed.

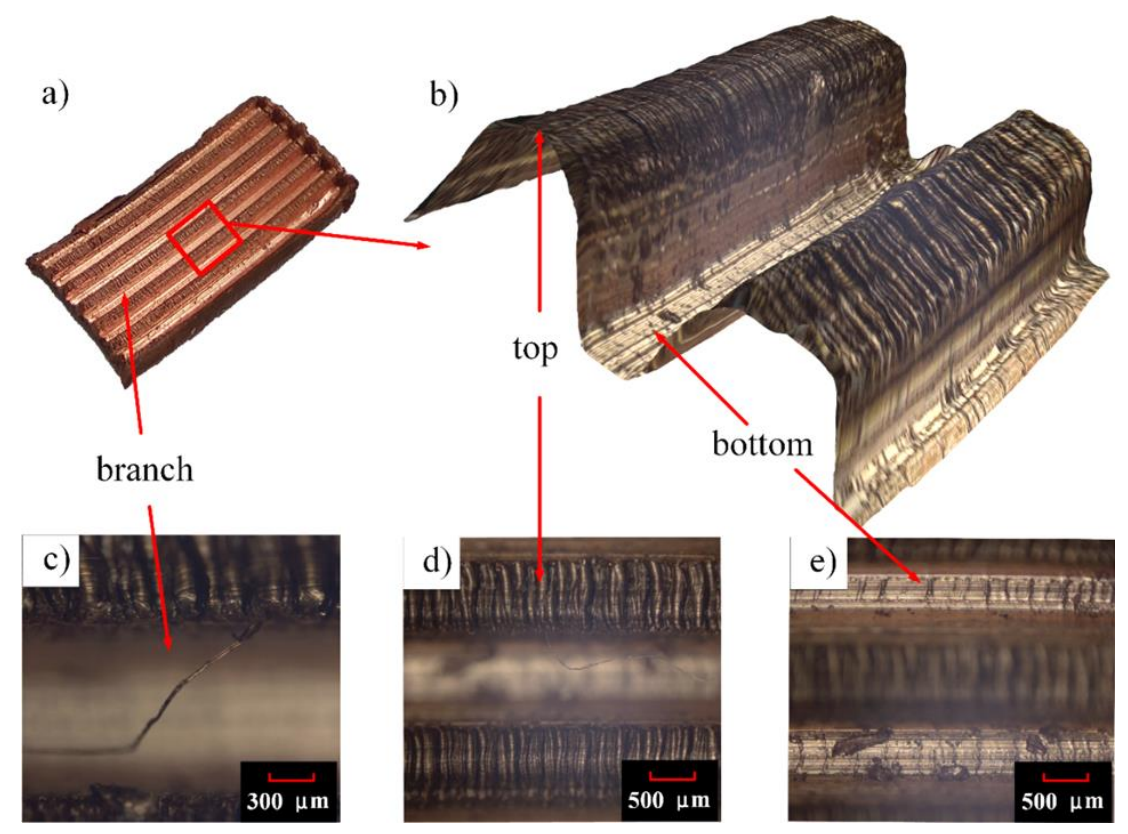

Figure 13: Substructure on groove surface with the structure isosceles trapezoid groove: a) sample;

b) 3D photo of micro structure; c) branches on surface; d) top and e) bottom of groove. 
These substructures could not only induce the occurrence of turbulent flow on the surface, but also increased the specific surface areas of the grooved strips, leading to a distinct increase in the workpiece heat exchange efficiency. The heat exchanger element with substructures also met the third generation standards of the heat transfer technology, as concluded by Bergles [14], while the industrial applications are in the transition from the second generation to the third generation. In the research of $\mathrm{Yu}$ et al. [15], the micro-grooves of the fins might have delayed the beginning of the condensation carryover phenomena, which improved the heat exchanger performance. This meant that the grooved strips produced by FEC, could work as fin plates in the heat exchanger, having a high potential in industrial applications.

\section{CONCLUSIONS}

In this study, a new chip recycling process, called Forming Extrusion Cutting, was developed and the fundamental features of this technique were investigated. The FEC is radically different from other available recycling processes, since it turns the removed material directly into grooved strips, instead of chips with irregular geometry. It could also be regarded as a non-chip manufacturing technique. Besides, resulting from the thermodynamic effect, on the FEC product surfaces unique substructures existed, which could not be easily fabricated through other plastic forming processes. The FEC has several advantages, such as high efficiency, energy and cost efficiency, as well as flexibility. The deformation process and forming performance of FEC were studied in this work, as along with the observation of the unique substructure on the FEC product surfaces.

(1) Grooved strips of regular size and with abundant substructures were successfully produced through FEC.

(2) Through FEM analysis, the deformation processes of FEC were simulated and could be divided into four phases. The distribution and variation of the effective stress, the effective strain and the strain rate during these phases were preliminary discovered along with the main cutting force. Simultaneously, both the generation and expansion of heat during machining were also researched. According to these investigations, the tooth forming mainly proceeded, while the material amount passing through the entrance of the forming channel and reaching the front part of the channel, led the parameters of this part to be the most critical effects on the forming results.

(3) During the forming performance evaluation of the samples, the relative error between the FEM data and the experimental data exceeded $10 \%$, displaying a high consistency. With reference to the measured data, among all structures, the forming conservation rates of the grooved strips reached a standard of $80 \%$, while the rectangle groove had the best performance with the forming conservation rate of $87.1 \%$.

(4) Through the samples observations with the ultra-deep microscope, the substructures such as grooves, cracks, wrinkles and branching were observed on the groove surfaces, which could induce the turbulent flow occurrence on the surfaces, highly expanding the specific surface area of the grooves. This provided the material with an advantage than the other groove fins with smooth surfaces regarding the heat transfer.

In conclusion, the FEC was proved to be workable as a chip recycling process as well as a process for grooved strips production. Through extrusion-cutting to transform machining chips directly into industry products, such as fin plates, provided a new direction for the chips recycling from machining.

Furthermore, to increase the specific surface area of the groove structure, as well as to improve the mechanical strength of the strip, future investigations were planned to examine the relationship between the working parameters and the deformation behaviour. Also, new radiated heat materials such as aluminium alloys should be utilized in experiments. 


\section{ACKNOWLEDGEMENT}

This research was conducted under the support of the National Nature Science Foundation of China (51375174), Fundamental Research Funds for Central Universities (2017ZD024), and Natural Science Foundation of Guangdong Province (s2013050014163, 2017A030313260).

\section{REFERENCES}

[1] Sherafat, Z.; Paydar, M. H.; Ebrahimi, R. (2009). Fabrication of A17075/Al, two phase material, by recycling Al7075 alloy chips using powder metallurgy route, Journal of Alloys and Compounds, Vol. 487, No. 1-2, 395-399, doi:10.1016/j.jallcom.2009.07.146

[2] Güley, V.; Ben Khalifa, N.; Tekkaya, A, E. (2010). Direct recycling of 1050 aluminum alloy scrap material mixed with 6060 aluminum alloy chips by hot extrusion, International Journal of Material Forming, Vol. 3, Suppl.1, 853-856, doi:10.1007/s12289-010-0904-z

[3] Paraskevas, D.; Dadbakhsh, S.; Vleugels, J.; Vanmeensel, K.; Dewulf, W.; Duflou, J. R. (2016). Solid state recycling of pure $\mathrm{Mg}$ and AZ31 Mg machining chips via spark plasma sintering, Materials \& Design, Vol. 109, 520-529, doi:10.1016/j.matdes.2016.07.082

[4] Behrens, B.-A.; Frischkorn, C.; Bonhage, M. (2014). Reprocessing of AW2007, AW6082 and AW7075 aluminium chips by using sintering and forging operations, Production Engineering, Vol. 8, No.4, 443-451, doi:10.1007/s11740-014-0542-2

[5] Luo, P.; McDonald, D. T.; Xu, W.; Palanisamy, S.; Dargusch, M. S.; Xia, K. (2012). A modified Hall-Petch relationship in ultrafine-grained titanium recycled from chips by equal channel angular pressing, Scripta Materialia, Vol. 66, No. 10, 785-788, doi:10.1016/ j.scriptamat.2012.02.008

[6] Shi, Q.; Tse, Y. Y.; Higginson, R. L. (2016). Effects of processing parameters on relative density, microhardness and microstructure of recycled $\mathrm{Ti}-6 \mathrm{Al}-4 \mathrm{~V}$ from machining chips produced by equal channel angular pressing, Materials Science and Engineering: A, Vol. 651, 248-258, doi:10.1016/j.msea.2015.11.002

[7] Liu, Y.; Li, Y. Y.; Zhang, D. T.; Ni, D. H.; Chen, W. P. (2002). Microstructure and properties of AZ80 magnesium alloy prepared by hot extrusion from recycled machined chips, Transactions of Nonferrous Metals Society of China, Vol. 12, No. 5, 882-885

[8] Gronostajski, J.; Marciniak, H.; Matuszak, A. (2000). New methods of aluminium and aluminium-alloy chips recycling, Journal of Materials Processing Technology, Vol. 106, No. 13, 34-39, doi:10.1016/S0924-0136(00)00634-8

[9] Moloodi, A.; Raiszadeh, R. (2011). Fabricating Al foam from turning scraps, Materials and Manufacturing Processes, Vol. 26, No. 7, 890-896, doi:10.1080/10426914.2011.577867

[10] Omoregie, A. (2013). Optimum compressive strength of hardened sandcrete building blocks with steel chips, Buildings, Vol. 3, No. 1, 205-219, doi:10.3390/buildings3010205

[11] Todic, V.; Cosic, I.; Maksimovic, R.; Tasic, N.; Radakovic, N. (2017). Model for simulation of life cycle costs at the stage of product development, International Journal of Simulation Modelling, Vol. 16, No. 1, 108-120, doi:10.2507/IJSIMM16(1)9.373

[12] De Chiffre, L. (1983). Extrusion cutting of brass strips, International Journal of Machine Tool Design and Research, Vol. 23, No. 2-3, 141-151, doi:10.1016/0020-7357(83)90013-6

[13] Yang, L.; Zheng, M. L. (2017). Simulation and analysis of ball-end milling of panel moulds based on Deform 3D, International Journal of Simulation Modelling, Vol. 16, No. 2, 343-356, doi:10.2507/IJSIMM16(2)CO9

[14] Bergles, A. E. (2002). ExHFT for fourth generation heat transfer technology, Experimental Thermal and Fluid Science, Vol. 26, No. 2-4, 335-344, doi:10.1016/S0894-1777(02)00145-0

[15] Yu, R.; Sommers, A. D.; Okamoto, N. C. (2013). Effect of a micro-grooved fin surface design on the air-side thermal-hydraulic performance of a plain fin-and-tube heat exchanger, International Journal of Refrigeration, Vol. 36, No. 3, 1078-1089, doi:10.1016/j.ijrefrig.2012.11.027 